$10-1-2020$

\title{
Acute symptomatic seizures in critically ill children: Frequency, etiology and outcomes
}

\author{
Sanam B. Rajper \\ Aga Khan University \\ Mujtaba Moazzam \\ Aga Khan University, mujtaba.moazzam@scholar.aku.edu \\ Arsheen Zeeshan \\ Aga Khan University, arsheen.zeeshan@aku.edu \\ Qalab Abbas \\ Aga Khan University, qalab.abbas@aku.edu
}

Follow this and additional works at: https://ecommons.aku.edu/

pakistan_fhs_mc_women_childhealth_paediatr

Part of the Neurology Commons, Neurosurgery Commons, and the Pediatrics Commons

\section{Recommended Citation}

Rajper, S. B., Moazzam, M., Zeeshan, A., Abbas, Q. (2020). Acute symptomatic seizures in critically ill children: Frequency, etiology and outcomes. Journal of Pediatric Neurosciences, 15(4), 375-378.

Available at: https://ecommons.aku.edu/pakistan_fhs_mc_women_childhealth_paediatr/1043 


\section{Original Article}

\section{Acute Symptomatic Seizures in Critically Ill Children: Frequency, Etiology and Outcomes}

\section{Sanam B. Rajper, Mujtaba Moazzam ${ }^{1}$, Arsheen Zeeshan, Qalab Abbas}

Department of Pediatrics and Child Health, Aga Khan University Karachi, Pakistan, ${ }^{1}$ Medical College, Aga Khan University Karachi, Pakistan
Background: Critically ill individuals have an increased risk of acute symptomatic seizures secondary to systemic illnesses; unrecognized or untreated seizures can quickly convert into status epilepticus, which is associated with high morbidity and mortality. Objective: The aim of this study was to determine frequency, etiology, and outcome of seizures in critical ill children admitted in intensive care unit of a tertiary care hospital. Materials and Methods: Retrospective review of medical records of all children admitted in pediatric intensive care unit (PICU) of the Aga Khan University from January 2016 to December 2018 and who had a new-onset seizure irrespective of underlying diagnosis was carried out after ethical review committee approval. Data were collected on a structured proforma; it included demographic information as well as relevant clinical and outcome information. The data were analyzed on Statistical Package for the Social Sciences (SPSS) software program, version 19.0. The descriptive statistics frequency and percentage was computed for qualitative variable. Mean and standard deviation were computed for quantitative variable, and univariate analysis was performed. Results: During the study period, a total 2053 patients were admitted in the PICU. One hundred six $(5 \%)$ had seizure. Sixty-three $(59.5 \%)$ were males. Meningitis 21 $(20 \%)$, sepsis $21(20 \%)$, complicated pneumonia $18(17 \%)$ were the major primary diagnosis in these children. Mean age of the study population was 75 months (standard deviation $[\mathrm{SD}] \pm 54.4)$ and $72(68 \%)$ were $<5$ years of age, whereas 63 $(59.5 \%)$ were males. The seizures lasted $>10 \mathrm{~min}$ in $10(10 \%)$ and were associated with high had neurological deficit $(P=0.001)$. We did not observe any correlation with electrolyte imbalance, renal failure, need of ventilator support with duration of seizure, and type of seizure $(P>0.005)$. Conclusion: Infection was the most common etiology associated with a new-onset seizure in children admitted in our PICU. Seizures lasting for $>10$ min were observed with high neurological deficit. We did not find any association of mortality with seizure duration.

KEYWORDS: Acute symptomatic seizure, antiepileptic drug (AEDs), critical ill children

\section{INTRODUCTION}

There is increased risk of seizures in critically 2 ill children secondary to systemic illnesses. Unrecognized/untreated seizures can quickly convert into generalized convulsive or more frequently into

Received: 25-10-2019, Revised: 15-01-2020, Accepted: 28-03-2020, Published: 19-01-2021.

\begin{tabular}{|l|l|}
\hline \multicolumn{2}{|c|}{ Access this article online } \\
\hline Quick Response Code: & Website: \\
& www.pediatricneurosciences.com \\
\cline { 2 - 3 } & \\
&
\end{tabular}

nonconvulsive status epilepticus, which is associated with high morbidity and mortality. ${ }^{[1]}$

Seizures can be seen as a result of an acute systemic illness, primary neurology pathology, or

Address for correspondence: Dr. Qalab Abbas, Assistant Professor, Department of Pediatrics and Child Health, Aga Khan University Hospital Karachi, Pakistan. E-mail: qalababbas@gmail.com

This is an open access journal, and articles are distributed under the terms of the Creative Commons Attribution-NonCommercial-ShareAlike 4.0 License, which allows others to remix, tweak, and build upon the work non-commercially, as long as appropriate credit is given and the new creations are licensed under the identical terms.

For reprints contact: wkhlrpmedknow_reprints@wolterskluwer.com

How to cite this article: Rajper SB, Moazzam M, Zeeshan A, Abbas Q. Acute symptomatic seizures in critically ill children: frequency, etiology and outcomes. J Pediatr Neurosci 2020;15:375-8. 
a medication side effect and can present in a wide array of symptoms from convulsive activity, subtle seizure and twitching, and altered mental status to lethargy. ${ }^{[1]}$ Nonconvulsive seizures are common in critically ill individuals with different presentation such as coma, confusion, lethargy, staring, agitation, aggression, automatism, blinking, crying, delirium, facial twitching, psychosis, unexplained tachycardia, laughter, and eye deviation. ${ }^{[2]}$

Incidence of seizures in the general population is approximately 40/100,000. Very limited studies are conducted on seizures in critically ill children admitted in pediatric intensive care unit (PICU). In a study from Valencia et al. $^{[3]}$ on seizure in PICU, reported that incidence of seizure in critically ill children was only $0.5 \%$, which was much lower than adult studies that showed incidence from $0.8 \%$ to $3.3 \%$ with vascular, metabolic, and drug withdrawal being the most common causes.

Electrographic seizures were observed in $(30 \%)$ critically ill children and were associated with high mortality and morbidity. Risk factors for electrographic seizures include younger age, clinical seizure prior to electroencephalography (EEG) monitoring, initial abnormal background in EEG, and a diagnosis of epilepsy. ${ }^{[4]}$

\section{Materials and Methods}

Retrospective review of medical records of all children admitted in PICU of the Aga Khan University from January 2016 to December 2018 and who had a newonset seizure irrespective of underlying diagnosis was carried out after ethical review committee approval (20180510-462). All information was recorded on a structured form. Data collection included demographic details, admitting diagnosis, details of seizures (type, duration and electrographic features) and imaging details. Data on PICU therapies such as need of inotropic support, need of renal replacement therapy, development of acute kidney injury, electrolyte imbalance, and cause of seizure with outcome in form death of patient or any neurological deficit post-seizure measured by Glasgow outcome scale (5: good recovery; 4: moderate disability; 3: severe disability; 2 : persistent vegetative state; 1 : death) at discharge were collected from medical record. The data was analyzed using Statistical Package for Social Sciences (SPSS IBM Corp., Armonk, NY, USA) version 19 for windows. The descriptive statistics frequency and percentage were computed for qualitative variables such as gender, diagnosis, type of seizure, and duration of seizure. Mean and standard deviation were computed for quantitative variable. Univariate analysis was performed.

\section{Results}

During the period of 3 years, a total of 2053 patients admitted in PICU, of which $106(5 \%)$ children had new-onset seizures. Mean age of the study population was 75 months (standard deviation [SD] \pm 54.4); $72(68 \%)$ were $<5$ years and $63(59.5 \%)$ were males [Table 1]. Underlying diagnosis were (sepsis: 21(20\%), meningoencephalitis: $21(20 \%)$, known case of epilepsy with status epilepticus 7 (6.5\%) complicated pneumonia $18(17 \%)$, road traffic accident $7(6.5 \%)$, congenital heart disease $3(3 \%)$, and others (post bone marrow transplant for thalassemia major, dengue hemorrhage fever, poisoning, inborn error of metabolism) 29 (27\%). Generalized seizures were present in $70(66 \%)$ and seizures were $<5 \mathrm{~min}$ of duration in $69(65 \%)$ patients. EEG findings were background slowing in $73(69 \%)$ patients, focal epileptic discharges $7(6.6 \%)$, generalized epileptic discharges $5(4.8 \%)$, status epilepticus $7(6.6 \%)$, and normal EEG in 14(13\%). Fifty-one (48\%) had no neurological deficits, 18 (17\%) had neurological deficits, and 37 (35\%) expired. Patient with refractory status epilepticus had worst outcome; all seven patients expired. Prolong duration of $>10 \mathrm{~min}$ of seizure more neurological deficit $(P=0.05)$. There is no association between type of seizure with outcome $(P=0.66)$, type of seizure with duration of seizure $(P=1.8)$, and duration of seizure with acute kidney injury $(P=0.17)$.

\section{Discussion}

This is the first study from a developing country on acute symptomatic seizure in critically ill children. Frequency of acute symptomatic seizure was $5 \%$ at our institute that is slightly higher than previous study conducted by Valencia et al. ${ }^{[3]}$ The possible reason for this observation is that children are exposed to infections more than as reported earlier. However, our values are lower than as reported by Sahin et al. ${ }^{[5]}$

Intravenous (IV) midazolam was used in all patients for cessation of seizure, followed by long-acting medication. The most commonly used longer acting antiepileptic drug (AED) used was IV levetiracetam 94 (89\%). Seven patients were treated as refractory status epilepticus, needed midazolam infusion, propofol infusion, IV methylprednisolone and IV immunoglobulin (IVIG). In two patients, no long-acting AEDs was used as the cause was hypocalcaemia. None of our patient developed respiratory depression after IV benzodiazepam as mentioned in the previous study. ${ }^{[5]}$

Electrolyte imbalance was observed in $94(88.6 \%)$ of patients. Sodium abnormalities including 
Rajper, et al.: Frequency, etiology and outcomes of symptomatic seizures in critically ill children

\begin{tabular}{|c|c|}
\hline \multicolumn{2}{|c|}{$\begin{array}{l}\text { Table 1: Characteristic of acute symptomatic seizure with } \\
\text { demographics }\end{array}$} \\
\hline Variables & Value \\
\hline Mean age (SD) in months & $75(\mathrm{SD} \pm 54.4)$ \\
\hline \multicolumn{2}{|l|}{ Age distribution } \\
\hline Less than 1 years & $38(36 \%)$ \\
\hline $1.1-5$ years & $34(32 \%)$ \\
\hline $5.1-10$ years & $12(11 \%)$ \\
\hline $10.1-18$ years & $22(21 \%)$ \\
\hline \multicolumn{2}{|l|}{ Gender } \\
\hline Male & $63(59.5 \%)$ \\
\hline Female & $43(40.5 \%)$ \\
\hline Male-to-female ratio & $1.5: 1$ \\
\hline \multicolumn{2}{|l|}{ Seizure occurred } \\
\hline Present with seizure in emergency room & $48(45 \%)$ \\
\hline Developed seizure in ICU & $58(55 \%)$ \\
\hline \multicolumn{2}{|l|}{ Type of seizure } \\
\hline Generalized seizure & $70(66 \%)$ \\
\hline Focal seizure & $32(30.2 \%)$ \\
\hline Subtle seizure & $4(3.8 \%)$ \\
\hline \multicolumn{2}{|l|}{ Seizure duration } \\
\hline Less than 5 min & $69(65 \%)$ \\
\hline $5-10 \mathrm{~min}$ & $27(25 \%)$ \\
\hline More than $10 \mathrm{~min}$ & $10(10 \%)$ \\
\hline \multicolumn{2}{|l|}{$\begin{array}{l}\text { Use of long antiepileptic drug (AEDs) } \\
\text { for seizure control after short-acting } \\
\text { drug }\end{array}$} \\
\hline One AED used & $87(82.2 \%)$ \\
\hline Two AEDs used & $10(9.4 \%)$ \\
\hline More than 2 & $7(6.6 \%)$ \\
\hline No AEDS used & $2(1.8 \%)$ \\
\hline \multicolumn{2}{|l|}{ Antiepileptic drug (AEDs) } \\
\hline $\begin{array}{l}\text { Midazolam (short acting to abort } \\
\text { seizure) }\end{array}$ & $106(100 \%)$ \\
\hline $\begin{array}{l}\text { Levetiracetam (as first long- } \\
\text { acting drug) }\end{array}$ & $94(89 \%)$ \\
\hline Phenobarbitone & $\begin{array}{l}14(13 \%) \text { (in three } \\
\text { patients as first AEDs, } \\
\text { in four patients as } \\
\text { second AEDs, and in } \\
\text { seven patients of status } \\
\text { epilepticus) }\end{array}$ \\
\hline Phenytoin & $\begin{array}{l}15(14 \%) \text { (in four } \\
\text { patients as first AEDs, } \\
\text { in four patients as } \\
\text { second AEDs, and in } \\
\text { seven patients of status } \\
\text { epilepticus) }\end{array}$ \\
\hline Sodium valproate & $\begin{array}{l}12(11 \%) \text { (in three } \\
\text { patients as first AEDs, } \\
\text { in four patients as } \\
\text { second AEDs, and in } \\
\text { seven patients of status } \\
\text { epilepticus) }\end{array}$ \\
\hline Midazolam infusion & $7(6.6 \%)$ \\
\hline Propofol infusion & $7(6.6 \%)$ \\
\hline \multicolumn{2}{|l|}{ Etiology } \\
\hline Sepsis & $21(20 \%)$ \\
\hline
\end{tabular}

\begin{tabular}{lc}
\hline \multicolumn{2}{c}{ Table 1: Continued } \\
\hline Variables & Value \\
\hline Meningoencephalitis & $21(20 \%)$ \\
Complicated pneumonia & $18(17 \%)$ \\
Road traffic accident & $7(6.5 \%)$ \\
Congenital heart disease & $3(3 \%)$ \\
Known case of epilepsy with status & $7(6.5 \%)$ \\
epilepticus & \\
Others (post bone marrow transplant & $29(27 \%)$ \\
for thalassemia major, dengue & \\
hemorrhage fever, poisoning, and & \\
inborn error of metabolism) & \\
Electrolyte imbalance & $94(88.6 \%)$ \\
Acute kidney injury & $81(76 \%)$ \\
Inotropic support & $98(91.6 \%)$ \\
Ventilator support & $93(86.9 \%)$ \\
EEG & \\
Abnormal & $92(86 \%)$ \\
Normal & $14(14 \%)$ \\
EEG finding & \\
Focal epileptic discharges & $7(6.6 \%)$ \\
Generalized epileptic discharges & $5(4.8 \%)$ \\
Status epilepticus & $7(6.6 \%)$ \\
Background slowing & $73(69 \%)$ \\
Normal & $14(14 \%)$ \\
Outcome & $37(35 \%)$ \\
Expired & $51(48 \%)$ \\
No neurological deficit & $18(17 \%)$ \\
Neurological deficit &
\end{tabular}

hypernatremia were observed in $38(35.5 \%)$ patients, whereas $22(20.2 \%)$ had hyponatremia. Other electrolyte abnormalities included hypocalcemia $(2 \%)$, hypokalemia $(29.9 \%)$, and hypomagnesemia $(1 \%)$. Although we did not observe any correlation with electrolyte imbalance with type of seizure and seizure duration $(P>0.05)$, in our opinion they are worth mentioning because these might precipitate seizures. ${ }^{[5]}$ In previous studies conducted in PICU, we also observed that electrolyte imbalance was not responsible for development of seizure. ${ }^{[3]}$ Another study on febrile seizure with acute gastroenteritis also did not show any significant electrolyte imbalance. ${ }^{[6]}$

EEG was performed in all patients; the most common finding was background slowing $73(69 \%)$, and the reason for background slowing might be encephalopathy or use of antiepileptic medication before the EEG was performed. We strongly suggest if seizures are stopped with short acting benzodiazepine, then wait for EEG, before loading with long-acting medication. Sahin et $a l .{ }^{[5]}$ also reported background slowing as common EEG finding in their study.

In our studies, male-to-female ratio is 1.5:1; of 106 children, $48(45 \%)$ critical ill children presented with seizure in 
emergency room and $58(55 \%)$ patients developed seizure during stay at PICU. Most common were generalized seizure $70(66 \%)$, focal $32(30.2 \%)$, and subtle seizure 4 $(3.8 \%)$; study on continuous video EEG monitoring has shown high incidence of subtle seizures that are difficult to recognize as these seizures have no discernible clinical correlate. ${ }^{[7]}$ Acute symptomatic seizure was $<5 \mathrm{~min}$ duration and controlled with single long-acting AEDs 87 $(82.2 \%)$. Sahin et al. ${ }^{[5]}$ also found short duration of acute symptomatic in critical ill children in their study.

The seizure lasting for $>10 \mathrm{~min}$ was observed with more morbidity with $P<0.005$. Although there was no increased mortality with increased duration of seizures observed, the neurological outcome was much worse in those with the seizure lasted $>10 \mathrm{~min}$. Payne et al. ${ }^{[7]}$ have reported that seizure lasted $>12 \mathrm{~min} / \mathrm{h}$ associates with poor neurological outcome but no association with mortality.

In our study, we did not observe any correlation with electrolyte imbalance, renal failure, need of ventilator support with type of seizure, and duration of seizure $(P>0.05)$.

Overall $35 \%$ patients expired and another $17 \%$ developed new-onset neurological deficit, which shows the overall severity of illness with which patients were admitted. It also emphasizes the need for early recognition and prompt management of seizures and also adequate monitoring of these patients (electrolytes and EEG) for development of seizures.

Our study has several limitations including but not limited to being a retrospective study, with small sample size reported from a single center and analysis limited to univariate. However, this is the first comprehensive report from this region describing the characteristics of patients who develop seizure in the PICU during a critical illness or injury.

\section{Conclusion}

The main conclusions drawn from this study are as follows:

- Infections especially sepsis, meningoencephalitis, and pneumonia were most common underlying diagnosis in our patients with seizure, followed by traumatic brain injury.

- Levetiracetam was the most common long-acting AED used in our cohort after midazolam.

- EEG was normal in $14 \%$ patients and there was slowing of background activity in another $69 \%$ of the patients.

- Children <5 year are more prone to developed seizure.

- Although there was no increased mortality with increased duration of seizures, the neurological outcome was much worse in those with seizure duration $>10 \mathrm{~min}$.

- No correlation was observed between acute kidney injury, electrolyte imbalance, need of ventilator support; on duration of seizure and type of seizures.

\section{Financial support and sponsorship}

Nil.

\section{Conflicts of interest}

There are no conflicts of interest.

\section{REFERENCES}

1. Ch'ang J, Claassen J. Handbook of clinical neurology neurological institute. New York, NY: Columbia University; 2017.

2. Jirsch J, Hirsch LJ. Nonconvulsive seizures: developing a rational approach to the diagnosis and management in the critically ill population. Clin Neurophysiol 2007;118:1660-70.

3. Valencia I, Lozano G, Kothare SV, Melvin JJ, Khurana DS, Hardison $\mathrm{HH}$, et al. Epileptic seizures in the pediatric intensive care unit setting. Epileptic Disord 2006;8:277-84.

4. Abend NS, Arndt DH, Carpenter JL, Chapman KE, Cornett KM, Gallentine WB, et al. Electrographic seizures in pediatric ICU patients: cohort study of risk factors and mortality. Neurology 2013;81:383-91.

5. Sahin S, Yazici MU, Ayar G, Karalok ZS, Arhan EP. Seizures in a pediatric intensive care unit: a prospective study. J Trop Pediatr 2016;62:94-100.

6. Ghorashi Z, Nezami N, Soltani-Ahari H, Ghorashi S. Convulsion following gastroenteritis in children without severe electrolyte imbalance. Turk J Pediatr 2010;52:301-5.

7. Payne ET, Zhao XY, Frndova H, McBain K, Sharma R, Hutchison JS, et al. Seizure burden is independently associated with short term outcome in critically ill children. Brain 2014;137:1429-38. 